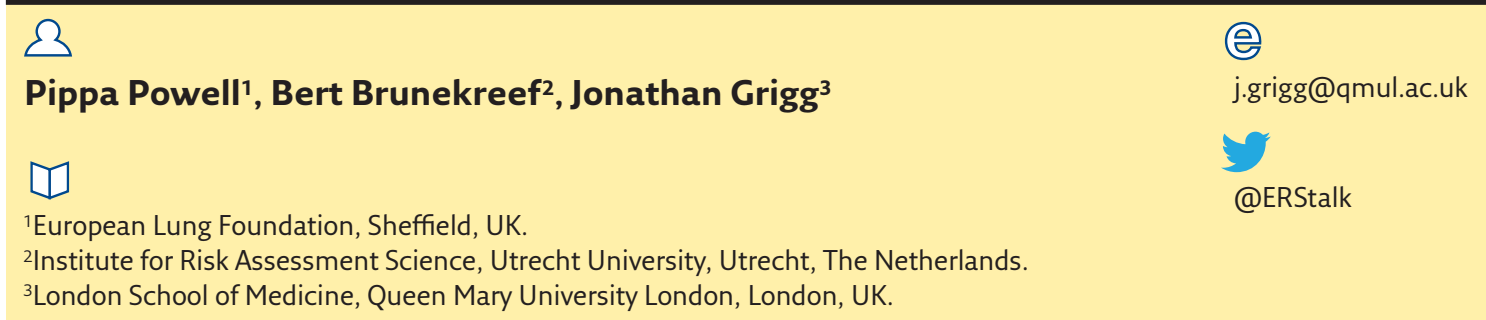

\title{
How do you explain the risk of air pollution to your patients?
}

A recent report by the Royal College of Physicians in the UK [1] has highlighted the pressing need for action on air quality, both in terms of awareness and education, and in order to try and take active measures to reduce pollution levels. The report has calculated that 40000 deaths are brought forward annually due to air pollution in the UK and highlighted that:

- air quality in many countries is getting worse;

- for many vulnerable populations, not enough is being done; and

- there is a lack of appreciation by patients and the public of the impact of air pollution on their health.

In March 2016, a workshop was convened by the European Respiratory Society (ERS) Environment and Healthy Committee (a subcommittee of the ERS Advocacy Council) in response to concerns among members of the ERS on the topic of "the risk of air pollution". The issue had been raised that many healthcare professionals (HCPs) are now faced daily with questions and concerns from patients about the impact that poor air quality can have on their health. This holds particularly true for individuals who suffer from chronic respiratory conditions, such as asthma and chronic obstructive pulmonary disease (COPD) [2].

\section{The problem}

The British Lung Foundation (www.blf.org.uk) and the Dutch Lung Foundation (Longfonds) (www. longfonds.nl), who were present at the workshop, set the scene with their views on public and patient needs. They highlighted that air pollution is impacting on people living with lung conditions (>65\% of Longfonds patients explained that they felt it was a problem for them), that parents are noticing the impact on their children, that there is strong public support for more pollution information and health advice, and that this information should be accessible, timely and, where possible, localised.

\section{Current knowledge}

The negative impact of poor air quality on human health is now well accepted, with many important papers having made the association between specific pollutants and human health clear, both in the short and long term [3-5]. These data have allowed for the developed of air quality indexes, scales that can alert individuals when the air quality is at levels that are harmful to human health [6-8].
Cite as: Powell P, Brunekreef $B$, Grigg J, et al. How do you explain the risk of air pollution to your patients? Breathe 2016; 12: 201-203. 
It is also now possible to have much more localised monitoring of individuals and their immediate environment. This has the capacity to allow for much more detailed studies linking air quality directly with health

\section{Gaps}

The workshop participants agreed that although the evidence is developing rapidly there are many gaps between this evidence and public understanding and awareness. Specifically, the workshop participants considered that for the public, the gaps included:

- the need to understand more about the longterm effects of poor air quality in a way that is comparable with other risk factors;

- the need to understand which actions an individual can make to reduce exposure, whilst ensuring healthy activities are still maintained and having no negative impact on activities of daily life; and

- the need to understand that each individual has a role to play to ensure that the air quality is as good as it can be.

The workshop participants felt that for patients, the gaps included:

- the need to understand how acute episodes of poor air quality will affect their own health and the actions they need to take to protect themselves; and

- the need for healthcare providers to have the tools to advise patients about air pollution and how to change their treatment plans or activities on high pollution days, and how to reduce long-term exposure.

Specific points that were highlighted are listed in table 1.
The workshop discussed the lack of guidance available to HCPs, particularly in primary care, on the topic of air quality. Two strategy reports focussing on asthma (Global Initiative for Asthma) [9] and COPD (Global Initiative for Chronic Obstructive Lung Disease) [10] were discussed, and in both cases, there was a negligible mention of air quality and no guidance given on how to advise patients. It was noted by the group that better guidelines are needed for HCPs with clear advice to give to respiratory patients with respect to longterm air quality and acute peaks, so that this can be integrated into an individual's care plan. There was also some discussion about whether primary care had a role to inform non-"at risk" patients about air quality. There was concern about whether this should be a priority with the limited time that HCPs have to spend with patients. The information on air quality in general should also be consistent with other patient groups (cardiovascular, diabetes, etc.).

The following gaps for HCPs were highlighted:

- links to useful information on outdoor air pollution for patients and HCPs;

- air quality updates;

- evidence-based advice in clinical guidelines for different patient groups (e.g. asthma and COPD); and

- treatment plans for individual patients regarding air pollution.

\section{Conclusion}

Respiratory and primary HCPs are key to ensuring that awareness of the importance of clean air is raised, that patients are getting the right advice with regards both short- and long-term exposure, and that they advocate at local, national and international levels for better air quality [11-13].

Table 1 Specific points about the effect of air pollution on health that were highlighted by the workshop participants

Information needs to be scientifically reliable

Personal experiences should be used to make it relevant for people

Individuals should be encouraged to take responsibility and action

The risk of air quality to an individual should be communicated to patients and to the general public

People should be informed of what actions they can take rather than just information about the health risks and/or pollution levels

Risk should be compared to other risks (e.g. environmental tobacco smoke and traffic accidents)

Social status should be considered

Advice should be practical

Information should be simple

The issue should be addressed in a way that is adapted to local needs in different countries 


\section{Actions}

In this issue of Breathe, there is a factsheet that has been developed for HCPs to enable them to better explain the risk of air pollution to patients. This attempts to put risk into a more meaningful format for individuals, and particularly those living with chronic lung conditions.

The European Lung Foundation (ELF) and the ERS will build on the outputs from the workshop and the factsheet to produce a toolkit for HCPs, which will be available at the ERS International Congress this year in London, UK, and available online after the event (www.healthylungsforlife. org). This toolkit will also contain a factsheet on outdoor air quality produced by the ELF and a booklet called Air Quality and Health produced by the ERS Environment and Health committee.

\section{Acknowledgements}

The following individuals who were part of the work on "How to explain the risk of air pollution to public patients and policy makers" are thanked by the authors for their contribution to the workshop and, hence, this editorial, and include: Bert Brunekreef (Chair of the ERS Environment and Health Committee), Jonathan Grigg (Secretary of ERS Paediatrics Assembly), Steven Wibberley (British Lung Foundation), Christine Strouss (Longfonds), Karin Lisspers (Chair of ELF Professional Advisory
There will be several sessions at the ERS International Congress on the topic including:

- on Tuesday, September 6, 2016, at 08:30-10:30 $\mathrm{h}$ in room L, there is a symposium on urban air pollution and human health;

- on Wednesday, September 7, 2016, at 08:30-10:30 h in the Prince Regent room, there is a session on health effects related to air pollution; and

- on Wednesday, September 7, 2016, at 10:45-12:45 h in the Prince Regent room, there is a symposium on occupational lung disease worldwide.

For the public, the ERS/ELF Healthy Lungs for Life campaign this year will focus once more on clean air, with events throughout London and the UK, and across the world in 2016-2017.

Committee), Luc Int Panis (VITO, Mol, Belgium), Nadia Vilahur (World Health Organization), Stephen Holgate (Chair of the ERS Science Council), Louise Duprez (European Environmental Bureau, Brussels, Belgium), Anne Stauffer (Health and Environment Alliance, Brussels), Nino Kuenzli (ERS Environment and Health committee), Francesco Forastiere (ERS Environment and Health committee), Christina Gratziou (ERS Advocacy Chair), Isabella Annesi-Maesano (ERS Environment and Health committee), Indre Butiene (ERS Environment and Health committee), Pippa Powell (ELF staff), Emma Thompson (ELF staff), Marine Faure (ERS staff) and Brian Ward (ERS staff).

\section{Conflict of interest}

P. Powell is an employee of the European Lung Foundation.

\section{References}

1. Royal College of Physicians. Every Breath We Take: the Lifelong Impact of Air Pollution. London, RCP, 2016.

2. Gibson JG, Loddenkemper R, Sibille Y, et al., eds. European Lung White Book. 2nd Edn. Sheffield, European Respiratory Society, 2013

3. World Health Organization. Ambient (Outdoor) Air Quality and Health. www.who.int/mediacentre/factsheets/fs313/en/Date last updated: March 2014. Date last accessed: March 2016.

4. Beelen R, Raaschou-Nielsen O, Stafoggia M, et al. Effects of longterm exposure to air pollution on natural cause mortality: an analysis of 22 European cohorts. Lancet 2014; 383: 755-844.

5. McCreanor J, et al. Respiratory effects of exposure to diesel traffic in persons with asthma. N EnglJ Med 2007; 6: 2348-2358.

6. Abelsohn A. Health effects of outdoor air pollution: approach to counseling patients using the Air Quality Health Index. Can Fam Physician 2011; 57: 881-887.

7. Li L, Lin GZ, Liu HZ, et al. Can the Air Pollution Index be used to communicate the health risks of air pollution? Environ Pollut 2015; 205: 153-160.
8. World Health Organization. Health and Environment: Communicating the Risks. Geneva, WHO, 2013.

9. Global Initiative for Asthma. Global Strategy for Asthma Management and Prevention. 2015. Available from: www. ginasthma.org

10. Global Initiative from Chronic Obstructive Lung Disease. Global Strategy for the Diagnosis, Management, and Prevention of COPD. 2015. Available from: www.goldcopd. org

11. Shofer S, Chen TM, Gokhale J, et al. Outdoor air pollution: counseling and exposure risk reduction. Am J Med Sci 2007; 333: 257-260.

12. Laumbach $\mathrm{R}$, Meng Q, Kipen $\mathrm{H}$. What can individuals do to reduce personal health risks from air pollution? J Thorac Dis 2015; 7: 96-107.

13. Kunzli N, Rapp R, Perez L. "Breathe clean air": the role of physicians and healthcare professionals. Breathe 2014; 10: 215-219. 